\title{
Deposition and Stripping Properties of Mercury on Iridium Electrodes
}

\author{
S. P. Kounaves ${ }^{*, 1}$ and J. Buffle \\ Department of Inorganic and Analytical Chemistry, University of Geneva, 1211 Geneva 4, Switzerland
}

\begin{abstract}
The reduction of mercury on a fresh iridium surface is reversible with a half-wave potential of $+162 \mathrm{mV}(v s$. SCE). A $\mathrm{Hg}(\mathrm{O})$ monolayer is formed by underpotential deposition (UPD) at $+600 \mathrm{mV}$ during the initial scans of a repetitive cyclic voltammogram. This monolayer acts as bulk $\mathrm{Hg}(\mathrm{O})$ during further cycles, and the reduction half-wave potential then shifts towards $+410 \mathrm{mV}$. Anodization of the electrode at a potential $>+1000 \mathrm{mV}$ returns the reduction wave to its original position. The peak for the oxidation of bulk $\mathrm{Hg}(\mathrm{O})$ from the surface occurs at $+430 \mathrm{mV}$ followed by a peak for the underpotential stripping (UPS) of the $\mathrm{Hg}(\mathrm{O})$ monolayer at $+650 \mathrm{mV}$. The quantity of $\mathrm{Hg}(\mathrm{O})$ for the monolayer corresponds to a $40 \%$ coverage of the Ir surface. The underpotential shift for the bulk and monolayer stripping of $\mathrm{Hg}(\mathrm{O})$ from Ir was found to be $210 \mathrm{mV}$. No indications of a $\mathrm{Hg}$-soluble compound formation between $\mathrm{Hg}$ and Ir were found.
\end{abstract}

The application of mercury film electrodes to speciation of trace elements in natural waters is presently limited either due to the bad stability or reproducibility of the $\mathrm{Hg}$ film in varying experimental conditions (e.g., Hg films on glassy carbon) or to the dissolution of the substrate in $\mathrm{Hg}$ and the formation of intermetallic compounds with the test metal ion (e.g., films on Pt). A detailed study of many substrates (1) showed that these problems could be overcome by using Ir as a substrate. Unfortunately, although the electrochemical behavior of mercury on substrates such as platinum, silver, gold, nickel, and carbon is well documented in the literature, the same cannot be said for iridium. During the past 30 years, only a few studies have dealt with mercury deposition on iridium, and these were mainly concerned with the behavior of mercury as a poison for hydrogen and oxygen adsorption on the surface of the electrode (2-4).

We report here the results of a study of the deposition and stripping properties of mercury at an iridium rotating disk electrode (Ir-RDE). The aim of this work was to quantify the parameters required to optimize the formation and stability of a true mercury film on an iridium substrate. This study was therefore directed to the determination of $(i)$ the reduction characteristics of $\mathrm{Hg}(\mathrm{II})$ on $\mathrm{Ir}$, (ii) the oxidation characteristics of $\mathrm{Hg}(\mathrm{O})$ from Ir, and (iii) the interactions of the Ir surface with $\mathrm{Hg}$ in terms of its solubility, the underpotential of deposition/stripping, and work function differences.

\section{Experimental}

Instrumentation.-The electrochemical system has been previously described (1). It consists of a microcomputer controlled potentiostat (Motorola EXORset + Tacussel PRG5), a custom built medium-exchange/flowthrough Plexiglas cell, and an inverted polarizing microscope (Leitz EPIVERT) allowing in-situ observation and photography.

The working electrode assembly was a Tacussel EDI-55442 rotating disk electrode (RDE) with a $1 \mathrm{~cm}$ Teflon tip into which a $2 \mathrm{~mm}$ diam $\times 10 \mathrm{~mm}$ long Ir cylinder (Heraeus $\mathrm{GmhH}$ ) was press fitted. The electrode was rotated at $1500 \mathrm{rpm}$ during the experiments. The counterelectrode was a $\mathrm{Pt}$ rod. The reference electrode, to which all potentials are referenced, was a SCE $(238 \mathrm{mV}$ vs. NHE) filled with a saturated $\mathrm{NaCl}$ solution and equipped with a $0.1 M \mathrm{NaNO}_{3}$ bridge.

Electrode pretreatment.- The electrode was initially polished with diamond spray pastes of decreasing size, the smallest of them being $1 \mathrm{\mu m}$ until a mirror-like surface could be seen under the microscope at 250 times. The electrode was then washed with deionized water and cathodized at $-2000 \mathrm{mV}$ for $5 \mathrm{~min}$ in degassed $1.0 \mathrm{M}$ $\mathrm{HNO}_{3}$. The electrode was kept in this solution until transferred to a test solution.

*Electrochemical Society Active Member

${ }^{1}$ Present address: Department of Chemistry, State University of New York at Buffalo, Buffalo, New York 14214
Reagents.-Unless otherwise indicated, all chemicals used were analytical reagent grade (Merck). The Hg(II) used for film formation, was prepared by dissolution of triply distilled mercury in nitric acid, followed by dilution with $0.1 \mathrm{M} \mathrm{HClO}_{4}$ to give $10^{-3} \mathrm{M} \mathrm{Hg(II),} \mathrm{unless} \mathrm{other-}$ wise indicated.

All solutions were prepared with $18 \mathrm{~mol} / \Omega$ water from a Millipore brand ion exchange system.

High-purity (99.95\%) nitrogen gas (Carbagas) was used to purge oxygen from solutions and to maintain a nitrogen blanket during experimentation.

\section{Results and Discussion}

General considerations.-One of the simpler and more direct methods for investigating the interactions of $\mathrm{Hg}$ and the Ir surface is to employ cyclic voltammetry, using a $\mathrm{Hg}(\mathrm{II})$ solution and a "defined" iridium surface. Such a
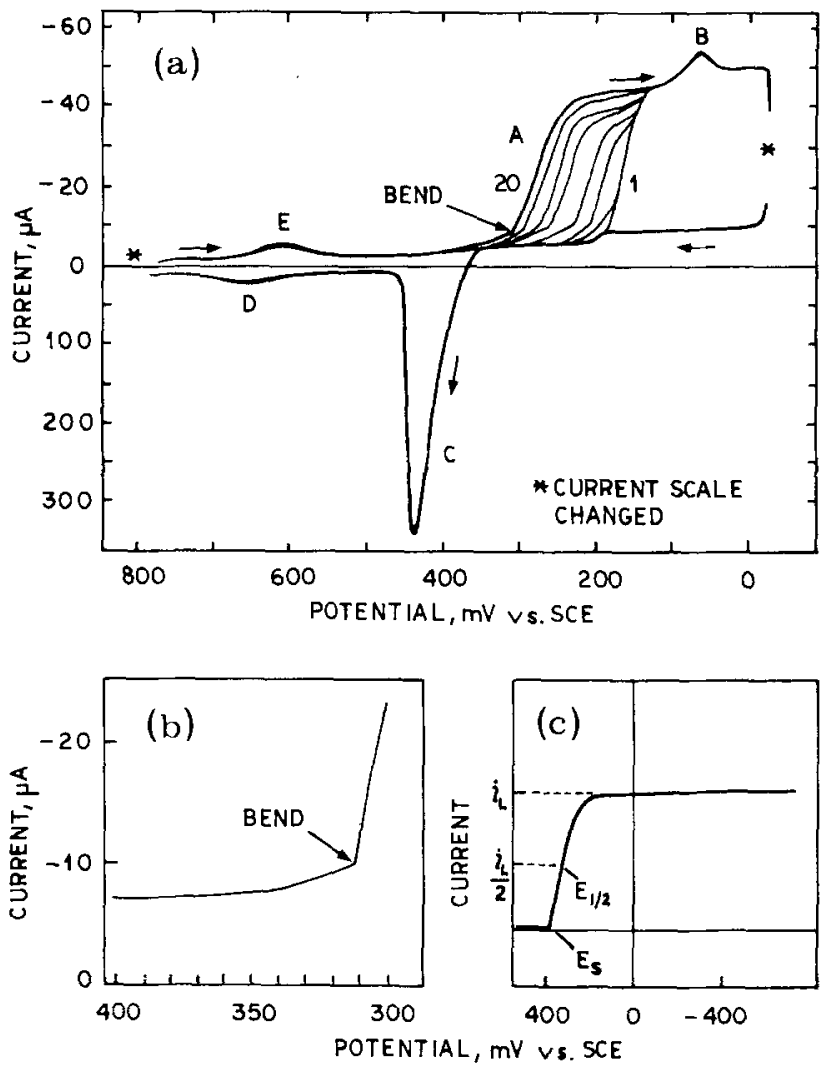

Fig. 1. (a) Consecutive cyclic voltammograms for reduction and oxidation of $\mathrm{Hg}$ on an Ir substrate. Conditions: $10^{-3} \mathrm{M} \mathrm{Hg}^{++}, 0.1 \mathrm{M} \mathrm{HClO}_{4}$, $v=20 \mathrm{mV} / \mathrm{s}$, and $\omega=1500 \mathrm{rpm}$, Note: Anodic-scan current scale is 5 times cathodic-scan current scale. (b) Enlargement of the "bend" at the foot of wave-A. (c) Reduction wave for $\mathrm{Hg}(\mathrm{I})$ or $\mathrm{Hg}(\mathrm{II})$ at a dropping mercury electrode. 
curve is shown in Fig. 1a with 20 consecutive repeating cycles.

For the cathodic scan, the most prominent features are the "shift" of the reduction wave-A from $\approx 160 \mathrm{mV}$ to 275 $\mathrm{mV}$, and peak-B which appears on top of wave-A at $\approx 70$ $\mathrm{mV}$. Furthermore, as can be seen, the reduction wave is not a clean sigmoidal shape as would be expected for the diffusion controlled reduction of $\mathrm{Hg}(\mathrm{II})$. It is complicated by a small bend (shown by the arrow) at the foot of the wave and a two-step reduction wave for the first six scans.

The interpretation of the curves in Fig. 1(a) requires taking into account the disproportionation reaction

$$
\mathrm{Hg}^{2+}+\mathrm{Hg}^{\circ} \longleftrightarrow \mathrm{Hg}_{\mathrm{s}}{ }^{2+}
$$

In fact, although the bulk of the solution contains only $\mathrm{Hg}(\mathrm{II})$ ions, as soon as some $\mathrm{Hg}(\mathrm{O})$ droplets are formed at the electrode surface, $\mathrm{Hg}(\mathrm{I})$ can be formed at the electrode surface as a result of reaction [1]. The equilibrium constant for reaction [1], $K$, can be computed from the Nernst relationship using the two couples $\mathrm{Hg}^{2+} / \mathrm{Hg}_{2}{ }^{2+}$ : $\left\{E_{\mathrm{o}}{ }^{\prime}\right\}$, and $\mathrm{Hg}_{2}{ }^{2+} / \mathrm{Hg}^{0}:\left\{\mathrm{E}_{\mathrm{o}}{ }^{\prime \prime}\right\}$ to give

$$
\begin{gathered}
E=E_{0}{ }^{\prime}+(R T / 2 \mathbf{F}) \ln \left(\left[\mathrm{Hg}^{2+}\right]^{2} /\left[\mathrm{Hg}_{2}{ }^{2+}\right]\right) \\
E=E^{\prime \prime}{ }_{0}+(R T / 2 \mathbf{F}) \ln \left(\left[\mathrm{Hg}_{2}{ }^{2+}\right]\right)
\end{gathered}
$$

where the symbols have their usual meaning. At any potential, subtraction of Eq. [2] from Eq. [3] gives

$$
\left.\log K=\ln \left(\mathrm{Hg}_{2}{ }^{2+}\right] /\left[\mathrm{Hg}^{2+}\right]\right)=\left(E^{\prime \prime}{ }_{0}-E_{0}{ }^{\prime}\right) \mathbf{F} / R T
$$

The value of $K$ for reaction [1] is $\approx 130$ at $25^{\circ} \mathrm{C}$ (5), so that at equilibrium, in a noncomplexing medium such as $\mathrm{HClO}_{4}$, the concentration of $\mathrm{Hg}(\mathrm{I})$ will be about 130 times greater than that of $\mathrm{Hg}(\mathrm{II})$. Thus, after the formation of a monolayer of $\mathrm{Hg}(\mathrm{O})$ on the Ir electrode, the reduction of $\mathrm{Hg}(\mathrm{II})$ will proceed in two steps

$$
\begin{aligned}
& \mathrm{Hg}^{2+}+\mathrm{Hg}^{0} \longleftrightarrow \mathrm{Hg}_{2}{ }^{2+} \\
& \mathrm{Hg}_{2}{ }^{2+}+2 \mathrm{e}^{-} \longleftrightarrow \longrightarrow 2 \mathrm{Hg}^{0}
\end{aligned}
$$

It has been shown that on a dropping mercury electrode (6) this two-step reduction gives rise to a single reduction wave of $\mathrm{Hg}(\mathrm{II})$. For solutions containing $\mathrm{Hg}(\mathrm{I})$, the reduction wave usually starts very abruptly, as shown in Fig. 1c (7, ch. 10). This is not the case for the Ir substrate, since $\mathrm{Hg}(\mathrm{I})$ must be formed at the surface by reaction [5]. However, it is very likely that the bend observed in Fig. 1 $\mathrm{a}$, b, is the equivalent to the point seen at $E_{\mathrm{s}}[\mathrm{Fig} .1 \mathrm{c}]$ for the dropping mercury electrode.

Reduction of mercury: wave-A.-The $\mathrm{Hg}(\mathrm{II})$ initially deposited during the cathodic scan (at $E<+200 \mathrm{mV}$ ), is mostly reoxidized during the anodic portion of the scan (peak-C). However, as will be shown below, at the start of the next cathodic scan, a monolayer of $\mathrm{Hg}(\mathrm{O})$ is either

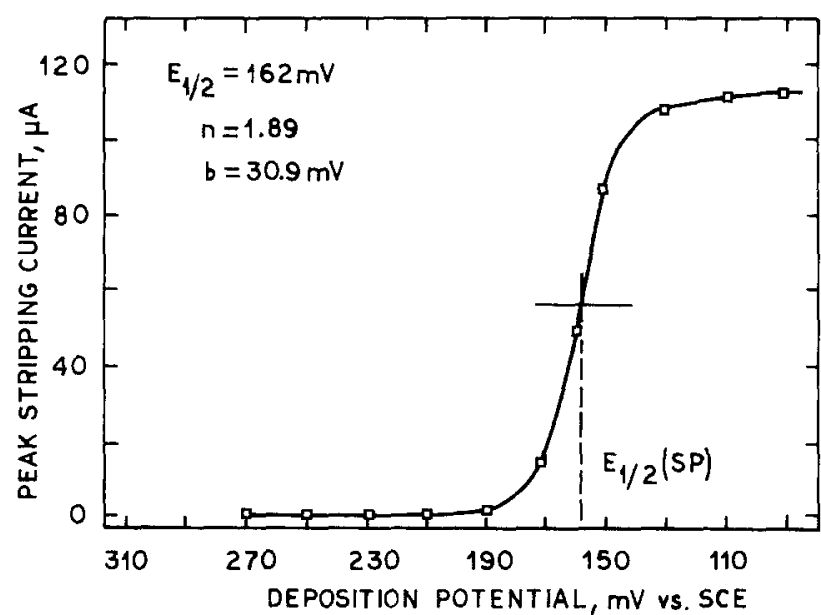

Fig. 2. The stripping polarography curve for the reduction of $\mathrm{Hg}$ (II) on Ir. Conditions: $10^{-4} \mathrm{M} \mathrm{Hg}^{++}, 0.1 \mathrm{M} \mathrm{HClO}_{4}, 10$ s depositions, $\omega=$ $1500 \mathrm{rpm}$, each point is the average of three separate measurements. still present (if the change in scan direction occurs at $E<$ $+600 \mathrm{mV}$ ) or reformed (when $E>+700 \mathrm{mV}$ ). On both Pt (8) and $\mathrm{Au}(9)$ a monolayer of $\mathrm{Hg}(\mathrm{O})$, which is difficult to oxidize, has been explained as being a result of chemical interaction between $\mathrm{Hg}$ and the substrate material. It will be shown later that Ir does not form a soluble compound with $\mathrm{Hg}$ (there are no amalgam oxidation peaks as there are for $\mathrm{Au}$ and $\mathrm{Pt}$ ), but that a $\mathrm{Hg}(\mathrm{O})$ monolayer is nevertheless formed between 600 and $400 \mathrm{mV}$. The positive shift in the $E_{1 / 2}$ value of wave-A and the limited growth of peak-E suggest that the monolayer coverage is only partial at first, but increases with the number of scans, becoming almost complete, as evidenced by the fact that $E_{1 / 2}$ approaches that for the reduction of $\mathrm{Hg}(\mathrm{I})$ or $\mathrm{Hg}$ (II) on the dropping mercury electrode. Its value can be computed from $E_{1 / 2}=E_{0}{ }^{\prime \prime}+(R T / 2 F) \ln \left(\left[\mathrm{Hg}^{2+}\right] / 2\right)$ [see Ref. (7) p. 167] and is $+410 \mathrm{mV}$ for the conditions used here $\left(\left[\mathrm{Hg}^{2+}\right]=0.001 M, E^{\prime \prime}{ }_{0}=510 \mathrm{mV}\right)$.

Note that the reduction wave can be made to return to its original position (cycle No. 1, Fig. 1a), either by applying a potential $>1000 \mathrm{mV}$ or by washing in concentrated nitric acid. Both of these treatments destroy the $\mathrm{Hg}$ monolayer formed between 600 and $400 \mathrm{mV}$.

Determination of $E_{1 / 2}$ for $H g(I I) \rightarrow H g(O)$.- - In attempting to measure $E_{1 / 2}$ for the reduction we must consider two limiting cases for the reduction of $\mathrm{Hg}$ (II) to $\mathrm{Hg}(\mathrm{O})$. Case a: Reduction onto $\mathrm{Hg}(\mathrm{O})$ already deposited on Ir, where the corresponding $E_{1 / 2}$ is given by wave-A-20 (Fig. 1a), $E_{1 / 2}(\mathrm{Hg})=275 \mathrm{mV}$. Case b: Reduction on pure Ir where $E_{1 / 2}(\mathrm{Ir})$ can be measured either from wave-A-1 (Fig. 1a) (1st cycle in cyclic voltammogram, $E_{1 / 2}(\mathrm{Ir})=170$ $\mathrm{mV}$ ); or by using stripping polarography (Fig. 2). This latter measurement, $E_{1 / 2}(\mathrm{SP})$, is graphically more precise, but less accurate since the surface is no longer purely Ir due to the longer reduction time. One would expect $E_{1 / 2}(\mathrm{SP})$ to change from $E_{1 / 2}(\mathrm{Ir})$ to $E_{1 / 2}(\mathrm{Hg})$ as the deposition time increases. For this reason deposition times approaching zero must be used to obtain a correct measurement of $E_{1 / 2}(\mathrm{Ir})$. In this way $E_{1 / 2}(\mathrm{Ir})=162 \mathrm{mV}$ (slope $=30.9$ $\mathrm{mV}$ and $n=1.88$ )

Reduction of mercury: peak-B.-This peak at $70 \mathrm{mV}$ is seen on the limiting current plateau during the cathodic scan and appears to grow slightly during the experiment (24-48h). During our studies it was discovered that peak-B disappeared when we changed to a freshly prepared solution of $\mathrm{HClO}_{4}+\mathrm{Hg}^{2+}$, and that it increased with the use of the solution. The increase being greatest during the first 2-5h and leveling off after 8-10h. Furthermore, changing to a different Ir substrate (an exact duplicate and pretreated the same as the first) in the same solution, the peak appeared unchanged, with the same height and shape.

In a further study, $200 \mu \mathrm{l}$ additions of $10^{-1} \mathrm{M} \mathrm{Hg}^{2+}$ were made, increasing the concentration from $10^{-3} M$ to $8 \times$ $10^{-3} \mathrm{M} \mathrm{Hg}^{2+}$. While the plateau at $250 \mathrm{mV}$ increased from 60 to $270 \mu \mathrm{A}$, peak-B did not change noticeably. Upon running the same voltammogram without the RDE rotating, reduction wave-A changed into a peak with a nonsymmetrical shape similar to that corresponding to a diffusion controlled process. Peak-B maintained the same size and shape (more or less symmetrical), indicating that it is a result of a surface-limited process.

These results lead us to conclude that this peak: (i) is not directly dependent on the concentration of either the $\mathrm{Hg}(\mathrm{II})$ or acid, and (ii) is a surface-limited phenomenon.

Interpretation of peak-B.-It is well known that $\mathrm{Hg}(\mathrm{I})$ may easily form insoluble salts with $\mathrm{Cl}^{-}$and $\mathrm{OH}^{-}$adsorbed on mercury (7). The formation of adsorbed $\mathrm{Hg}_{2} X_{2}$, in dc polarography with the DME, results in a reduction postwave according to

$$
\mathrm{Hg}_{2} \mathrm{X}_{2} \longleftrightarrow \mathrm{Hg}_{2}{ }^{2+}+2 \mathrm{X}^{-}+2 e^{-} \longleftrightarrow 2 \mathrm{Hg}^{0}
$$

With the RDE, this postwave is transformed into an adsorption "post"-peak. As will be shown below, this reaction is the origin of peak-B.

In our system the $\mathrm{OH}^{-}$is at a very low concentration $\left(10^{-13} \mathrm{M}\right)$, but the concentration of $\mathrm{Hg}(\mathrm{I})$ or $\mathrm{Hg}(\mathrm{II})$ may be 
as high as $10^{-1} M$ at the electrode surface. Using the solubility products for the $\mathrm{Hg}(\mathrm{I})$ and $\mathrm{Hg}$ (II) hydroxides, and the stability constants for $\mathrm{HgOH}^{+}, \mathrm{Hg}(\mathrm{OH})_{2}{ }^{\circ}, \mathrm{HgOH}_{3}{ }^{-}$, $\mathrm{Hg}_{2} \mathrm{OH}_{3}{ }^{+}$, and $\mathrm{Hg}_{2}(\mathrm{OH})_{2}{ }^{2+}$ indicates that formation of the solids is unlikely and that only $\mathrm{HgOH}^{+}$and $\mathrm{Hg}_{2}(\mathrm{OH})_{3}{ }^{+}$ could possibly form at the surface. But these species are unlikely to be adsorbed. The only possible source of $\mathrm{Cl}^{-}$ ions was the SCE reference electrode, in spite of the fact that a $\mathrm{NaNO}_{3}$ bridge was used between the SCE and the solution. The origin of the $\mathrm{Cl}^{-}$in solution explains the slow increase of reduction "post" peak-B and its disappearance when changing the test solution. The presence of $\mathrm{Cl}^{-}$should also produce a wave corresponding to the reoxidation of $\mathrm{Hg}(\mathrm{O})$ in the presence of $\mathrm{Cl}^{-}$, the limiting current of which is controlled by the diffusion of the $\mathrm{Cl}^{-}$ at the surface (7). Such a wave is indeed observed at about $+200 \mathrm{mV}$ (Fig. 1a). From the value of the limiting current, the concentration of the $\mathrm{Cl}^{-}$was estimated to be $2.0 \times 10^{-5} \mathrm{M}$ using a value of $2.1 \times 10^{-5} \mathrm{~cm}^{2} / \mathrm{s}$ for the diffusion coefficient of $\mathrm{Cl}^{-}$. This concentration was checked by placing the same SCE-bridge combination in the cell with $25 \mathrm{ml}$ of $0.1 \mathrm{M} \mathrm{HClO}_{4}$, and measuring the concentration of $\mathrm{Cl}^{-}$every hour using DPP with a DME. After $16 \mathrm{~h}$ the concentration of $\mathrm{Cl}^{-}$in the cell was found to be $\approx 3 \times$ $10^{-5} \mathrm{M}$, confirming the contamination value estimated above.

Although peak-B resulted from unforeseen $\mathrm{Cl}^{-}$contamination, the situation turned out to be useful for confirming that the reduction mechanism is linked to the production of $\mathrm{Hg}(\mathrm{I})$ formed by the reaction of $\mathrm{Hg}(\mathrm{II})$ with the monolayer of $\mathrm{Hg}(\mathrm{O})$, formed between 600 and 400 $\mathrm{mV}$. This was tested by applying various initial potentials between 1000 and $100 \mathrm{mV}$ to the electrode for $30 \mathrm{~s}$, after which the quantity of $\mathrm{Hg}_{2} \mathrm{Cl}_{2}$ formed was followed by recording peak-B with a single cyclic voltammogram. The value of $30 \mathrm{~s}$ was chosen, since the height of peak- $B$ was found to be dependent on time for periods of less than 30 s. In Fig. 3 we can see the peak-B (thus the quantity of $\mathrm{Hg}(\mathrm{I})$ formed) increases as a function of the initial potential for $E>600 \mathrm{mV}$, and abruptly decreases at $E<$ $100 \mathrm{mV}$. In other words, peak-B appears only under conditions where $\mathrm{Hg}(\mathrm{O})$ exists at the electrode surface and disappears in the potential range where $\mathrm{Hg}_{2} \mathrm{Cl}_{2}$ is directly reduced.

A final closer examination of peak-B (Fig. 1a) shows that the limiting current on the cathodic side of peak-B is larger than on the anodic side. This is consistent with the existence of an adsorbed $\mathrm{Hg}_{2} \mathrm{Cl}_{2}$ layer for two reasons: (i) once it is reduced to $\mathrm{Hg}(\mathrm{O})$, there is an increase of mercury surface available for further reduction of $\mathrm{Hg}(\mathrm{II})$, and (ii) cathodic of peak- $\mathrm{B}$, the $\mathrm{Hg}_{2} \mathrm{Cl}_{2}$ is reduced as soon as it reaches the surface.

Monolayer properties of mercury on iridium.-Nature of peaks $C, D$, and $E$.- Of the three stripping peaks that appear in Fig. 1a, peak-C (430 mV) is easily explained in terms of the oxidation of $\mathrm{Hg}(\mathrm{O})$ to $\mathrm{Hg}(\mathrm{I})$, which in a noncomplexing medium occurs at about $420 \mathrm{mV}$ (vs.

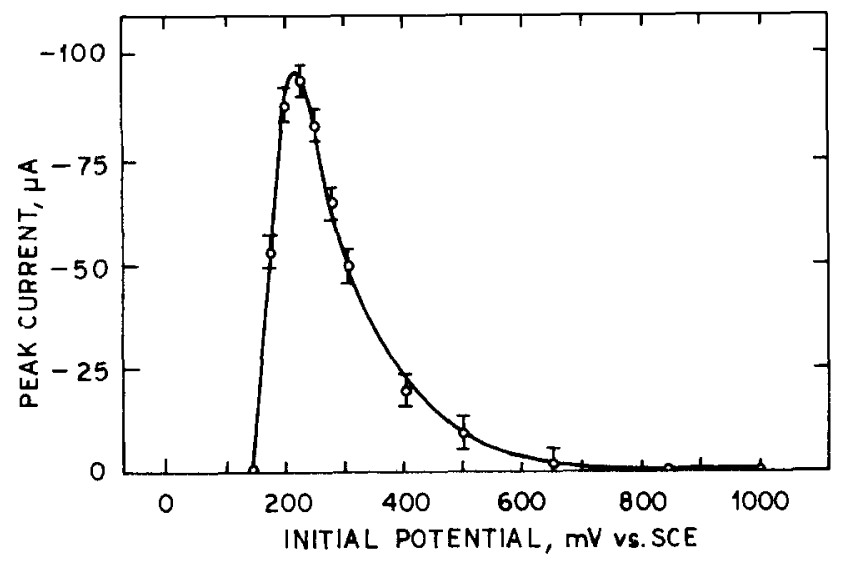

Fig. 3. The dependence of peak-B height on the starting scan potential (same conditions as Fig. la).

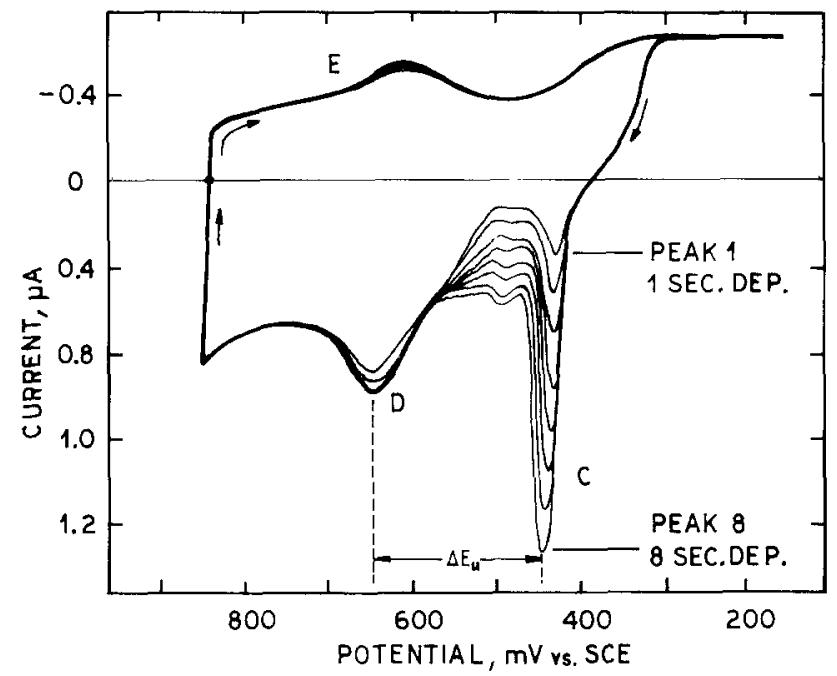

Fig. 4. Consecutive cyclic voltammograms for the oxidation peaks of $\mathrm{Hg}$ from the Ir substrate. Conditions: same as Fig. 1(a), except for concentration of $\mathrm{Hg}(\mathrm{II})=10^{-4} \mathrm{M}$.

SCE) (7). The second, barely visible, peak at $\approx 500 \mathrm{mV}$ (Fig. 4, not labeled) is $\mathrm{Hg}(\mathrm{I}) \rightarrow \mathrm{Hg}(\mathrm{II})$. The third, broader oxidation peak-D at $\approx 650 \mathrm{mV}$ is of special interest, however. As previously mentioned, in the cases of $\mathrm{Pt}$ and $\mathrm{Au}$, this area is sometimes occupied by several larger peaks. In these metals the peaks are due to the oxidation of $\mathrm{Au}-\mathrm{Hg}$ or Pt-Hg intermetallic compounds (8-10).

In order to identify peak-D on Ir, a second set of $\mathrm{CV}$ curves were made with the same conditions as in Fig. 1a, except that the concentration of mercury was $10^{-} 4 M$ and a higher sensitivity was used. In addition, the potential was held at $100 \mathrm{mV}$ for an increasing amount of time so as to deposit more mercury between each scan. The results are shown in Fig. 4. Peak-D increases slightly at first with the increased mercury deposition but eventually reaches a limit, while peak-C continues to increase with time at $100 \mathrm{mV}$. One can also notice that there is a reduction peak-E, whose evolution is parallel to that of peak-D. We thus conclude that peak-D is due to the oxidation of a layer of $\mathrm{Hg}$ possessing different properties in relation to the surface, since it is oxidized at an underpotential of stripping (UPS) and reduced at a corresponding underpotential of deposition (UPD) (peak-E). As will be shown, these peaks can be attributed to the formation/oxidation of a monolayer of $\mathrm{Hg}$.

Quantity of mercury corresponding to peak-D.-For all square lattice metals, such as $\mathrm{Pt}, \mathrm{Au}$, and $\mathrm{Pd}$, it has been shown (8) that $\mathrm{Hg}$ is also deposited in a square lattice and that its atomic radius is equal to $1.57 \times 10^{-8} \mathrm{~cm}$. Therefore, since iridium is also a square lattice metal, it is assumed here that this value is correct for the radius of $\mathrm{Hg}$ deposited at UPD on Ir. Using this value we can calculate that a monolayer of $\mathrm{Hg}$ contains $1.74 \times 10^{-9} \mathrm{~g}$ atom $/ \mathrm{cm}^{2}$ and that the charge necessary for stripping one monolayer of mercury from the Ir should be $330 \mu \mathrm{C} / \mathrm{cm}^{2}$.

The area of peak-D was found to correspond to a total charge of $5.63 \times 10^{-6} \mathrm{C}$, or $179 \mu \mathrm{C} / \mathrm{cm}^{2}$. With the roughness factor, estimated to be $\approx 1.3(8)$ for an Ir substrate polished to a mirror finish with $1.0 \mu \mathrm{m}$ diamond paste, this charge corresponds to an estimated mercury surface coverage of $42 \%$. A similar value of $38 \%$ was obtained from the corresponding reduction peak-E. An average surface coverage of $40 \%$ is reasonable since we are not using a single-faced Ir crystal and thus the available active sites will vary depending on the orientation of the Ir lattice.

It is interesting to note that the above result implies that the partial monolayer of $\mathrm{Hg}$ on Ir behaves, particularly in terms of the half-wave reduction potential, as if it were bulk $\mathrm{Hg}$

The underpotential shift.-By assuming that there is no soluble compound formed by reaction between the $\mathrm{Hg}$ layer and substrate, Kolb et al. (12) have derived an 


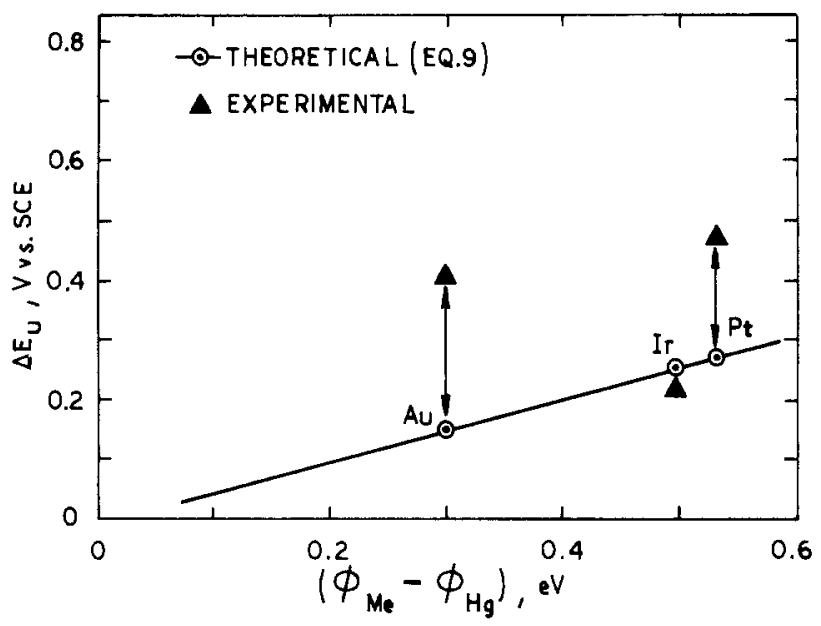

Fig. 5. Underpotential shift $\Delta E \mathrm{u}$ as a function of the difference in work-functions $\Delta \phi$ of substrate and $\mathrm{Hg}$.

expression predicting the monolayer-bulk underpotential shift, $\Delta E_{\mathrm{u}}$, from the work-function difference, $\Delta \phi$, of the substrate and monolayer material

$$
\Delta E_{\mathrm{u}}=\alpha \Delta \phi \quad \text { with } \alpha=0.5 \mathrm{~V} / \mathrm{eV}
$$

The corresponding value for Ir has never been calculated or experimentally determined. Using the workfunction values for Ir and $\mathrm{Hg}$, given by Trasatti (13), of 4.97 and $4.50 \mathrm{eV}$, respectively, we obtain a calculated value of $\Delta E_{\mathrm{u}}$ (theoretical) $=235 \mathrm{mV}$. Using the peak potentials (Fig. 4) of $430 \mathrm{mV}$ (peak-C) and $650 \mathrm{mV}$ (peak-D) for the bulk and monolayer stripping, the difference of which is independent of the $\mathrm{Hg}$ (II) concentration, we find $\Delta E_{u}$ (experimental) $=220 \mathrm{mV}$. Considering the uncertainties in the values of $\phi$, this value is in good agreement with theory. It has been shown (12) that the relationship between $\Delta \phi$ and the half-width, $b$, of the monolayer peak can be described by a Temkin-type isotherm, and from that data [Fig. 7 in (12)] we can predict that $b$ (for $\Delta \phi \approx 0.5$ ) should fall between 100 and $150 \mathrm{mV}$. Our results of $b=130 \mathrm{mV}$ is also in agreement with this value.

A very interesting point can be made in terms of showing the type of interaction responsible for the $\mathrm{Hg}-\mathrm{Ir}$ bond. Given below in Fig. 5 is a plot of the theoretical values of $\Delta E_{\mathrm{u}}$ and $\Delta \phi$ (according to Eq. [9]) for $\mathrm{Au}, \mathrm{Pt}$, and $\mathrm{Ir}$, and the experimentally determined values for $\mathrm{Au}$ and Pt from Ref. (12) and for Ir from this work. The results indicate that Ir does not form any intermetallic compounds with $\mathrm{Hg}$. On the other hand, both $\mathrm{Pt}$ and $\mathrm{Au}$ do form such compounds with $\mathrm{Hg}$ ( $\mathrm{Au}$ a bit more than $\mathrm{Pt}$ ), thus their experimentally measured underpotential shift includes a contribution from the chemical bonding (vertical arrows), whereas Ir shows no such contribution.

\section{Acknowledgments}

The authors gratefully acknowledge the technical assistance of M. L. Tercier, F. Bujard, and C. Bernard. This work was supported by the Swiss National Foundation (Project 2.413-0.82).

Manuscript submitted Feb. 14, 1986; revised manuscript received April 25, 1986.

\section{REFERENCES}

1. S. P. Kounaves, Ph.D. Thesis, University of Geneva, Geneva, Switzerland (1985).

2. A. D. Semenova, T. G. Fedotova, and G. Khomchenko, Vestn. Mosk. Univ., Ser. II, Khim., 20:6, 47 (1965).

3. Y. M. Maximov, V. E. Kazarinov, and O. A. Petrii, Electrokhimiya, 8, 1254 (1972).

4. M. Chemeris, A. Stromberg, N. Kolpakova, and Y. Vasil'ev, Electrokhimiya, 11, 1060 (1975).

5. J. F. Coetzee, in "Treatise on Analytical Chemistry," Part 2, Vol. 3, I. M. Kolthoff and P. Elving, Editors p. 231, Interscience Publishers Inc., New York (1961).

6. I. M. Kolthoff and C. S. Miller, J. Am. Chem. Soc., 63, $2732(1941)$.

7. J. Heyrovsky and J. Kuta, "Principles of Polarography," Czechoslovak Academy of Sciences, Prague (1965).

8. M. Z. Hassan, D. Untereker, and S. Bruckenstein, J. Electroanal. Chem., 42,161(1973).

9. L. A. Schadewald, T. R. Lindstrom, W. Hussein, E. E. Evenson, and D. C. Johnson, This Journal, 131, 1583 (1984).

10. W. G. Sherwood, and S. Bruckenstein, ibid., 125, 1098 (1978).

11. T. R. Lindstrom and D. C. Johnson, Anal. Chem., 53, 1855 (1981).

12. D. M. Kolb, M. Przasnyski, and H. Gerischer, J. Electroanal. Chem., 54, 25 (1974).

13. S. Trasatti, ibid., 33, 351 (1971).

\title{
Some Alternate Fabrication Processes for Molten Carbonate Fuel Cell Electrolyte Structures
}

\author{
W. D. Pasco and R. H. Arendt * \\ Ceramics Branch, Inorganic Materials Laboratory, General Electric Company, Corporate Research and Development, \\ Schenectady, New York 12301
}

\section{ABSTRAC'T}

Results are presented on experiments to develop low temperature fabrication techniques for the electrolyte structure of molten carbonate fuel cells. In addition, a derivative process was developed for the distortion-free filling of the electrodes with electrolyte, prior to their assembly into the cell.

The electrolyte structure, or tile, used in a molten carbonate fuel cell consists of a mixture of liquid alkali metal carbonates retained by capillarity in the interstices of an array of chemically inert inorganic crystallites. At cell operating temperatures, the carbonates form an ionically conducting liquid (1). The structure is conventionally fabricated by hot-pressing a finely particulate, intimate, matrix-electrolyte composite mixture. The process involves heating the die and mixture to temperatures $5-15 \mathrm{~K}$

* Electrochemical Society Active Member. below the electrolyte liquidus ( $\sim 764 \mathrm{~K}$ for the 62 mole percent $(\mathrm{m} / \mathrm{o}) \mathrm{Li}_{2} \mathrm{CO}_{3}-\mathrm{K}_{2} \mathrm{CO}_{3}$ composition) and applying pressures of up to $60 \mathrm{MPa}$ for $15-120 \mathrm{~min}$. The entire cycle, including heating and cooling of the apparatus, requires a minimum of $4 \mathrm{~h}$. Structures in excess of $1.5 \mathrm{~m}^{2}$ have been successfully prepared in this fashion. However, commercial applications of molten carbonate fuel cells will require tens of thousands of square meters of electrolyte matrix in units exceeding $1.0 \mathrm{~m}^{2}$. The capital and time intensive nature of hot-pressure indicates a need for an alternate fabrication process. 